\title{
Mapping Flood Events Using Remote Sensing in an Arid Zone River, Central Australia
}

\author{
$\underline{\text { R. Zhuang }}{ }^{\alpha}$, J. Costelloe $^{\alpha}$ and D. Ryu ${ }^{\alpha}$ \\ ${ }^{\alpha}$ Department of Infrastructure Engineering, The University of Melbourne, Victoria 3010 \\ Email: r.zhuang@pgrad.unimelb.edu.au
}

\begin{abstract}
Rivers in arid and semi-arid zones are distinguished by high variations in flow patterns both in spatial and temporal scale. The variable flows, often ephemeral, have a strong impact on the local hydrological, ecological and landscape characteristics. In Australia, rivers in the arid zone are often ungauged and therefore little information is available for further hydrological and ecological analysis. An assessment of the water resources and ecological importance of these rivers requires the fundamental information on the occurrence and extent of flow events. Remote sensing technologies can be applied where ground field data are few, or completely absent, but have rarely been operationally applied as the spatial and temporal resolutions of the sensors have traditionally been considered to be inadequate for mapping short-term flood events or those obscured by vegetation. However, the relationship between flow events and the following vegetation response can provide a useful indirect measurement of flow occurrences. Arid regions typically have low vegetation content and greenness for most of the year but the provision of water via a flow pulse can cause abrupt increases in vegetation density and greenness for a period following the flow event.
\end{abstract}

This paper explores a method using daily observations of the Normalized Difference Vegetation Index (NDVI) collected by the Moderate Resolution Imaging Spectrometer (MODIS) onboard the Terra satellite to map flow events in the Neales River catchment of the Lake Eyre Basin, Australia. MODIS bands 1 and 2 of 250-m spatial resolution surface reflectance are used to quantify NDVI. Larger flow events result in significant areas of open water, which are directly observed by negative NDVI values, while smaller events are implied by an increase in NDVI along the river channels a certain period after a flow pulse (Figure 1).

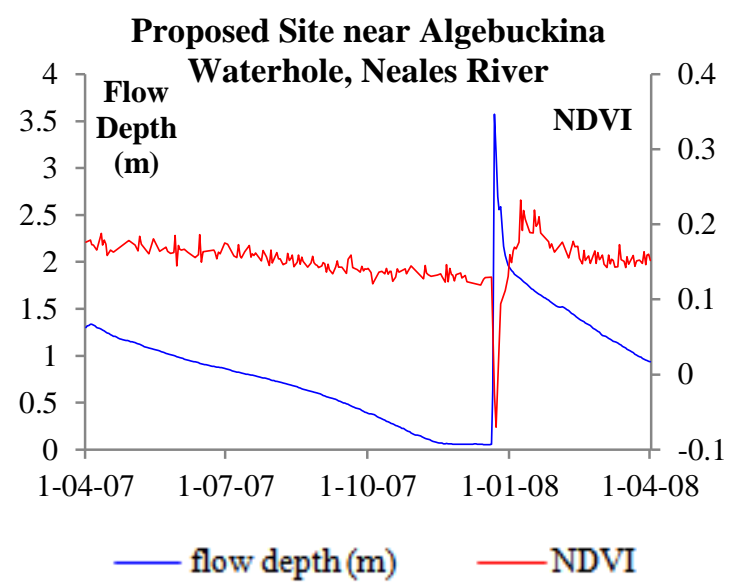

Figure 1. NDVI response to a flow event at the proposed river monitoring site
Flow size, floodplain width, vegetation type and vegetation density are considered as the major factors which influence the NDVI response during the flow periods. It is inferred that errors in timing the flow occurrences can be moderated by refined site selection, while characterising flow size and duration is more complicated.

Keywords: Ephemeral, Neales River, flow events, Terra MODIS 


\section{INTRODUCTION}

An assessment of the water resources and ecological importance of arid zone rivers requires the fundamental information of the occurrence and extent of flow events. However, in Australia, rivers in the arid zones are often ungauged and therefore little information is available for further analysis on how ephemeral rivers influence the hydrology, ecology and landscape (Costelloe et al., 2005). Hydrological modelling has been a common approach in such cases; nevertheless, well-developed models originally generated for humid catchments are typically not applicable in arid zones where the characteristics of hydrology and geomorphology greatly differ from water abundant regions (Walker et al., 1995). One solution to identify flows in poorly gauged or ungauged areas is the application of remote sensing instruments, including the Moderate Resolution Imaging Spectrometer (MODIS), though the spatial and/or temporal resolution of the sensors has been a universally recognised problem (Smith, 1997; Mertes, 2002; Jackson, 2008; Ticehurst et al., 2009).

Probably the most distinctive feature of arid zone rivers is the highly variable flow patterns, both in spatial and temporal scales (Walker et al., 1995; Capon, 2005; Costelloe et al., 2005). It is recognised that arid regions typically have low vegetation content and greenness for most of the year but the provision of water via a flow pulse can cause abrupt increases in vegetation density and greenness for a period following the flow event (Capon, 2005; Westbrooke \& Florentine, 2005). This enables the acquisition of hydrological information via earth surface response which can be monitored by remote sensing. Recently MODIS has been regarded as a useful data source for hydrological studies due to its relatively high spatial and temporal resolution (Ticehurst et al., 2009). MODIS-based Normalized Difference Vegetation Index (NDVI) is, at present, a viable and common input for the analysis of earth surface features, especially vegetation density (Weier \& Herring, 2011).

This study tests the utility of Terra MODIS 250-m surface reflectance data to estimate flow occurrences in the Neales River catchment, an arid zone river in central Australia. The hypothesis is that NDVI collected by MODIS can be used to identify flow occurrences via two types of surface responses: (1) the surface responses from open water in the river channels as direct measurements of the flow events $(\mathrm{NDVI}<0)$; $(2)$ the surface responses from vegetation surrounding the river channels and within the floodplain as indirect indicators, which are expected to be normally weak $(\mathrm{NDVI}<0.2)$ but evidently stronger (NDVI>0.2) for a period following a flow event. NDVI values are used as quantitative measurements of the surface responses. The time series of MODIS-generated NDVI are then verified against ground flow observations at multiple locations, and factors which affect the capacity of the proposed method are discussed.

\section{THE NEALES RIVER CATCHMENT}

Figure 2 shows an example NDVI map of the study area, the Neales River catchment. The input for the NDVI map was collected by MODIS onboard Terra on $7^{\text {th }}$ Apr 2000, following a large flood event. The major river channels are distinguished by red (higher NDVI) in this satellite image, and the rest of the area is basically bare land with little vegetation (lower NDVI). The catchment occurs in the western Lake Eyre Basin (LEB) and comprises the Neales River and its major tributary Peake Creek, both ephemeral systems. The river has a course of $430 \mathrm{~km}$ before it discharges into Lake Eyre North at approximately sea-level (Costelloe et al., 2005). The Neales River catchment occupies an area of $34,415 \mathrm{~km}^{2}$ with averaged annual precipitation, pan evaporation rate and areal potential evaporation rate of approximate $140 \mathrm{~mm}, 3760 \mathrm{~mm}$, and $1340 \mathrm{~mm}$ respectively (Costelloe et al., 2005).

Early knowledge of the Neales River catchment mainly covers the soil properties, sedimentology and climate patterns (Croke et al., 1996, 1998; McKenzie et al., 2000). Little hydrological information about the frequency of flow events was available, except for a rough estimation of one or two flow occurrences per year with a comparatively large flood inundation every ten years (Kotwicki, 1986). This knowledge gap was later filled by a field data collection project since 2000, providing accurate and detailed timing, duration, and relative size of flow events from several loggers at the accessible locations in the upstream and downstream reaches of the Neales River and Peake Creek (Costelloe et al., 2005).

Within the catchment, six flow monitoring sites with three additional control sites (bare hillslopes) are selected for investigation in this study. The flow monitoring sites are depicted in Figure 1 as squares, while the control sites as triangles. The site information of floodplain, vegetation/soil type and approximate vegetation density are listed in Table 1. 
Table 1. Site Characteristics

\begin{tabular}{|l|l|l|l|}
\hline Site Name & $\begin{array}{l}\text { Floodplain } \\
\text { Width }(\mathbf{m})\end{array}$ & $\begin{array}{l}\text { Vegetation// } \\
\text { Soil Type }\end{array}$ & $\begin{array}{l}\text { Approx. } \\
\text { Density }\end{array}$ \\
\hline $\begin{array}{l}\text { Algebuckina } \\
\text { Waterhole }\end{array}$ & 1050 & $\begin{array}{l}\text { eucalyptus } \\
\text { (coolibah) }\end{array}$ & medium \\
\hline $\begin{array}{l}\text { South Stewart } \\
\text { Waterhole }\end{array}$ & 1250 & $\begin{array}{l}\text { eucalyptus } \\
\text { (coolibah) }\end{array}$ & high \\
\hline $\begin{array}{l}\text { Algebuckina } \\
\text { Bridge }\end{array}$ & 500 & $\begin{array}{l}\text { eucalyptus } \\
\text { (coolibah) }\end{array}$ & high \\
\hline Peake Bridge & 800 & shrubs & medium \\
\hline Mid Peake & 3400 & shrubs & low \\
\hline Lora Creek & 1900 & gidgee & medium \\
\hline
\end{tabular}

Generally, the selected sites along the Neales River are covered by medium or high density of eucalypts (Eucalyptus coolabah), while sites along the Peake Creek are covered by shrubs or gidgee (Acacia cambagei) trees of low or medium density. Floodplain width, vegetation type and vegetation density are expected to be among the factors which influence the MODISbased NDVI response.
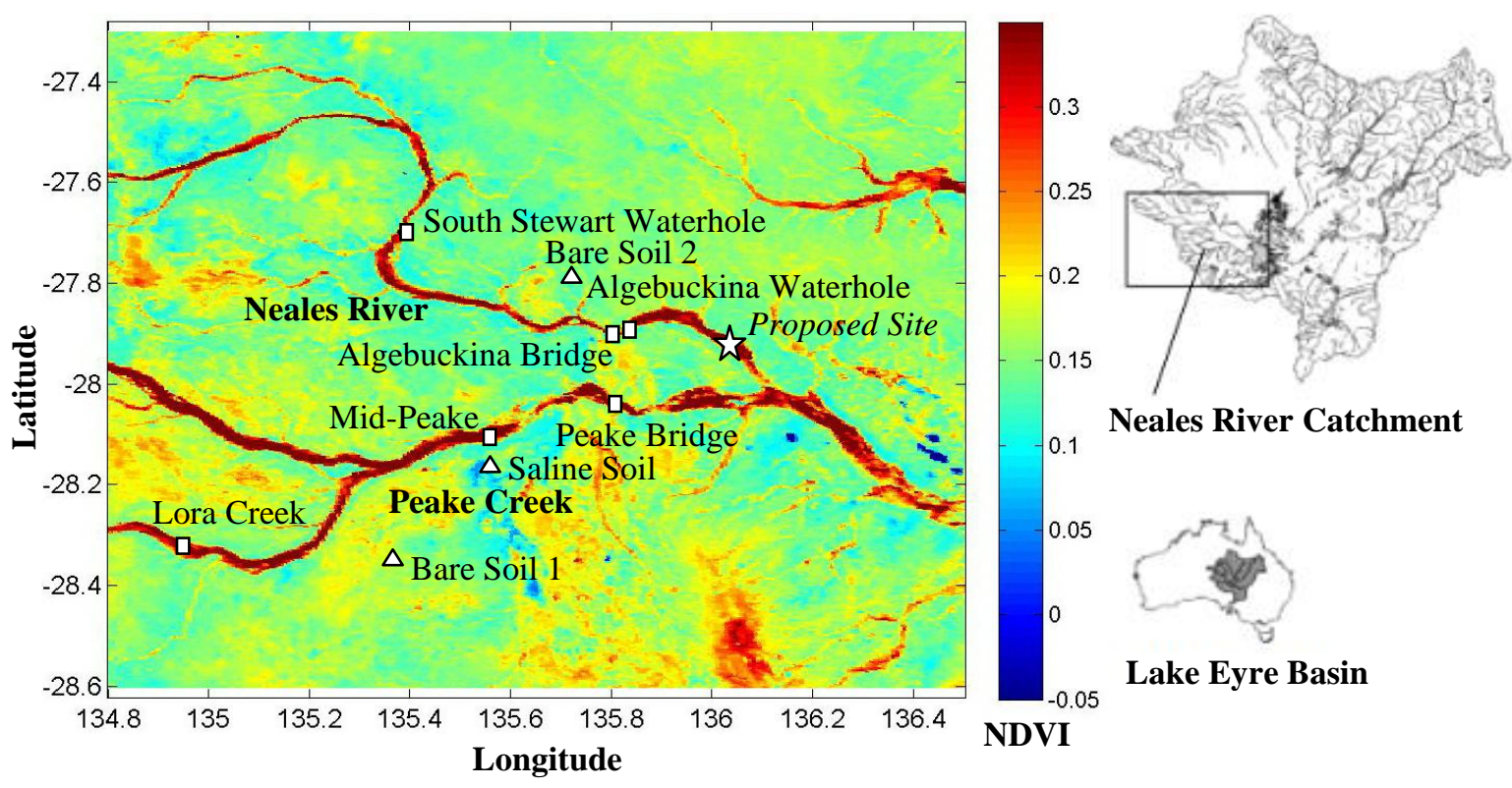

Neales River Catchment

Figure 2. The Neales River Catchment

\section{METHOD}

Based on the long-term flow records at all six study sites, a flow event in December 2007 was selected for investigation. It is a typical arid zone flow event of moderate magnitude and short duration. The previous significant flow event was in January 2007. One year's data records from 01/04/2007 to $31 / 03 / 2008$ are used in this study. The six river study sites (Figure 2) were deliberately selected at the same locations of the water level loggers in order to compare the flow records with the corresponding MODIS-based NDVI response.

Terra MODIS daily 250-m surface reflectance data were extracted via the USGS MODIS Reprojection Tool Web Interface (MRTWeb). MODIS provides 36 bands of spectral data, among which the reflectance of visible light (band 1, VIS) and near-infrared light (band 2, NIR) were used in this study. The satellite data were filtered by the MODIS cloud mask (MOD35_L2) before any further calculation because the cloud effect during the flow period has been proven to be a common negative factor (Ticehurst et al., 2009).

The Terra MODIS data were then converted to NDVI via equation (1):

$$
\mathrm{NDVI}=(\mathrm{NIR}-\mathrm{VIS}) /(\mathrm{NIR}+\mathrm{VIS})
$$

Common ranges of NDVI suggested by Weier and Herring (2011) are: <0 for water; around 0.1 for bare land of rock and sand; 0.2 to 0.3 for shrubs and grassland; 0.6 to 0.8 for temperate and tropical rainforests.

During 2000 to 2010, NDVI of 0.3 was visually identified as a strong vegetation response in the Neales River catchment (see Figure 2). Higher NDVI values are concentrated along the major river channels 
and floodplains, while the vast area of bare hillslope is characterised by NDVI values around 0.15 . It can be inferred from Figure 2 and the common NDVI ranges that, in arid zones, vegetation response is typically weaker than in humid regions. One reason is that the vegetation greenness is weaker in arid zones due to insufficient water supply. The other is that the vegetation cover is usually very sparse and mixed with bare soil, which results in low averaged NDVI value within one pixel of the satellite image.

The time series of NDVI at all selected sites were obtained for the study flow period. The trend lines of NDVI time series were further analysed to calculate site background NDVI (represented by yearly median values) and to perform the Worsley Likelihood test to determine whether and when (quantified as Lag 1) the vegetation response shows any evident increase (but not necessarily reaches the maximum NDVI) a certain period following the flow events. The confidence level of the Worsley Likelihood test is set to be 0.05 ( $95 \%$ confidence). Maximum NDVI increments and the temporal differences (quantified as Lag 2) between the date of flow occurrences and the following maximum NDVI are also calculated as a complement to the Worsley Likelihood test.

\section{RESULT}

The results at individual sites are presented by graphs of NDVI time series versus the corresponding flow records (Figure 3) and one summary table (Table 2). The NDVI time-series show that the NDVI response can have high variance, though the actual response is supposed to be rather smooth, because in arid zones, the available amount of water for plant greenness does not change significantly except when flow events or rainfall occur. Probable reasons for the daily variance could be variations in atmospheric conditions, location or footprint errors where there is heterogeneity between vegetated and non-vegetated areas at the pixel scale, or that MODIS-based NDVI is very sensitive to cloud effects. In order to obtain sufficient images for analysis, the cloud masking criteria were relaxed, which leads to inevitable daily variance and an overall underestimation of NDVI. Although excessively noisy as the daily data are, they are used in this study as an attempt to define the specific time of peak flow during a flow event, which has always been a challenge when using remote sensing. To moderate the variance in the data, the maximum NDVI of a 10-day moving window is used as the trend of the time series of vegetation response at each site, assuming little change in vegetation growth due to water deficiency (except during the period of flow events) and the general underestimation by cloud effects.

Figure 2 shows that only the Algebuckina Bridge site on the Neales River demonstrates a confident increase in NDVI following the significant flow occurrence on Dec $22^{\text {th }} 2007$, although the NDVI response contains a high overall variance. The floodplain at this site is relatively narrow with generally denser vegetation cover among all the study sites (Table 1). The magnitudes of NDVI changes at the other study sites are relatively small and could be mistaken as seasonal responses because the vegetation greenness is typically higher in winter and lower in summer in arid zones due to the seasonal variance in potential evapotranspiration and water stress (Willem et al., 2008). To justify that the NDVI changes following the major flow event in December are not seasonal, the Worsley Likelihood tests on the NDVI trends identify significant increases in the vegetation responses 9 to 29 days after the date of the peak flow (Table 2) when it was mid-summer and the plant growth should have been inhibited.

Based on the trend tests (Lag 1) and the periods (Lag 2) corresponding with the maximum NDVI increments, the NDVI response to the flow event at Algebuckina Waterhole is very slow with a small total increment due to the long-term water provision caused by the slow drawdown of standing water in the channelised waterhole. The speed of NDVI response to the flow occurrence is much improved at the South Stewart Waterhole which has similar site characteristics to the Algebuckina Waterhole but visibly denser vegetation cover across the floodplain corresponding with its higher yearly median value of NDVI. The NDVI increase at Algebuckina Bridge after the major flow event is of high magnitude but almost equally slow as at Algebuckina Waterhole. As for the Peake Bridge site, the three adjacent flow occurrences correspond with over $50 \%$ of daily NDVI values being filtered out the by the cloud masks during the critical period of the 3 flow events (from mid-October to late-February). Therefore, the result at this site is not as reliable. The Lora Creek site has a fairly wide floodplain and medium density of vegetation (mainly gidgee trees) and the increasing rates of NDVI following the two flow events are moderate in magnitude but show a rapid response. 


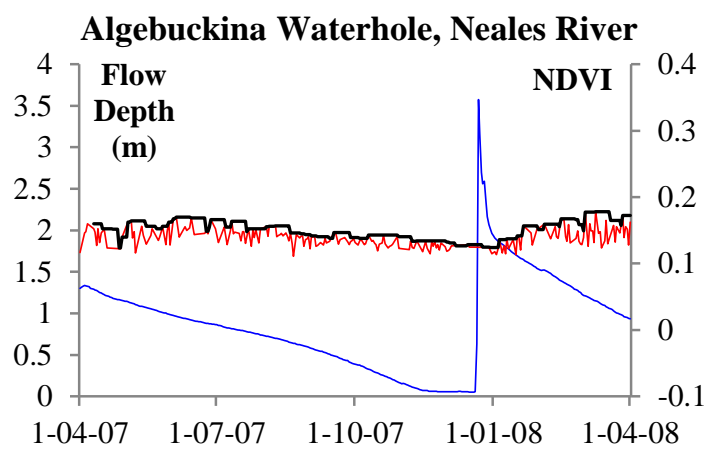

Algebuckina Bridge, Neales River

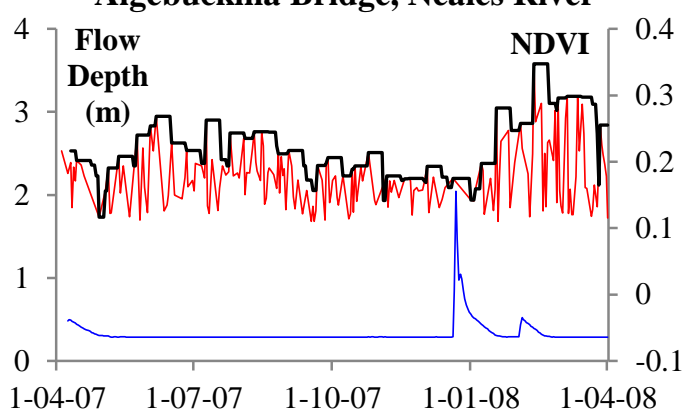

Mid-Peake

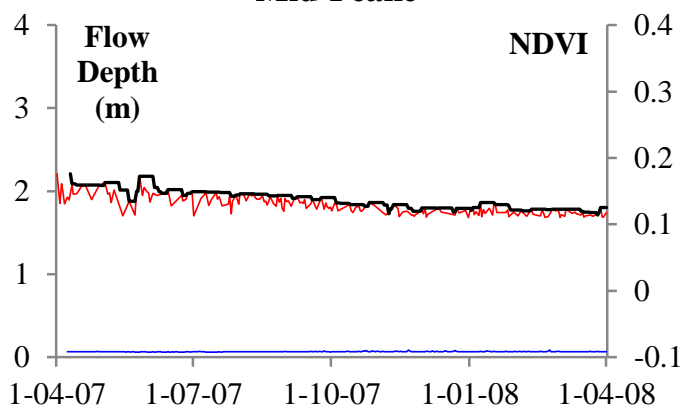

Control Sites

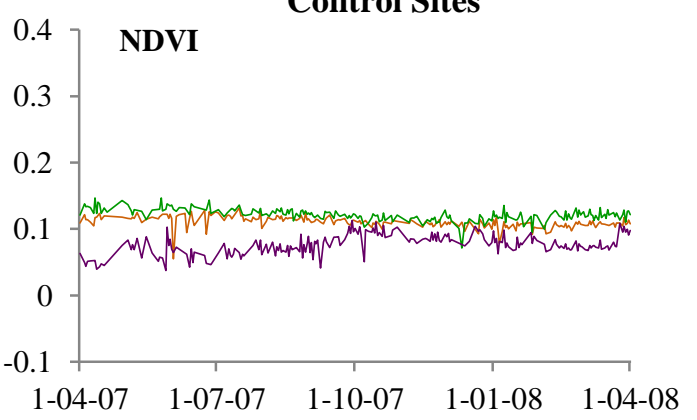

- flow depth $(\mathrm{m})$ NDVI
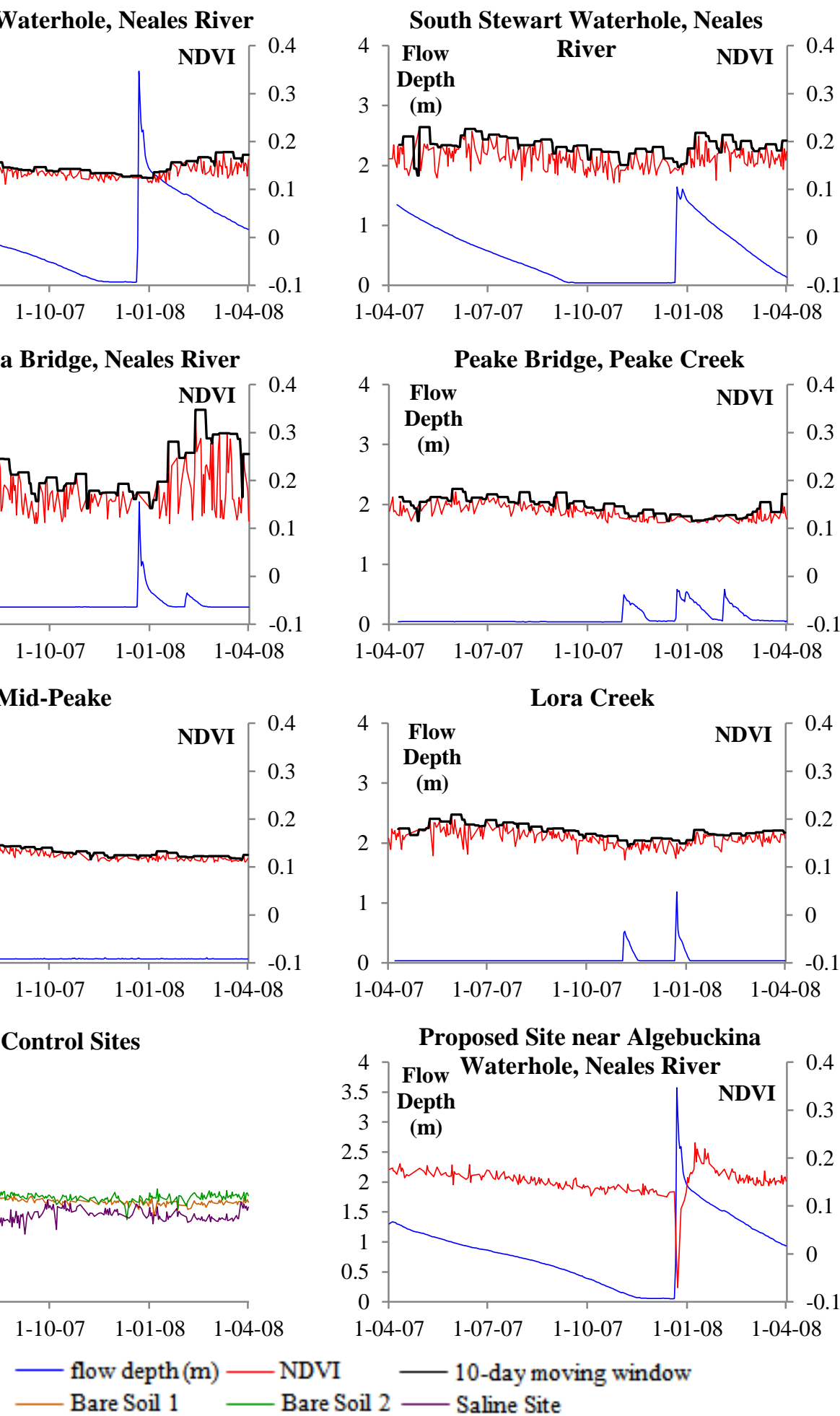

Peake Bridge, Peake Creek

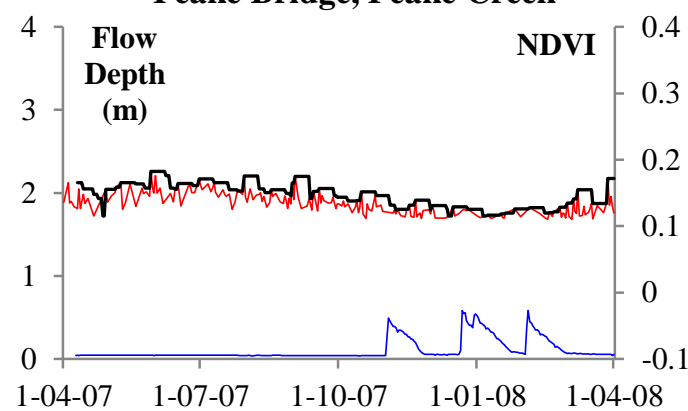

Lora Creek

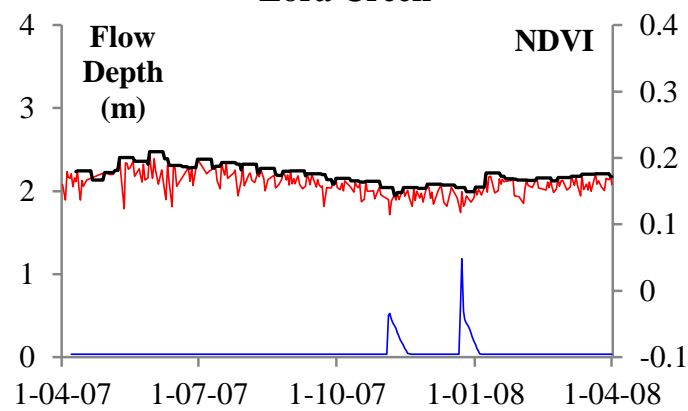

Proposed Site near Algebuckina

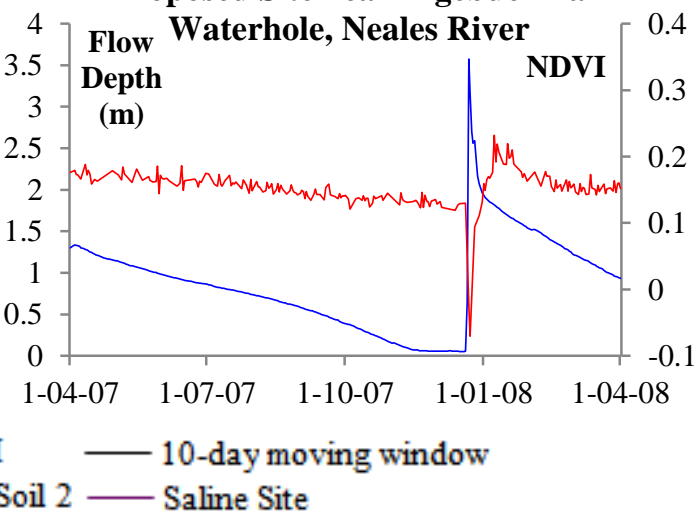

Figure 3. NDVIs and Flow Depths at the Investigated Sites

Mid-Peake can be regarded as a control site in the river systems as no flow events occurred during the study period. This site has a wide floodplain, dry condition and sparse vegetation cover and no distinguishable seasonal variation in NDVI is observed (Figure 3 and Table 2). This indicates that at least under these site conditions, the previously mentioned seasonality of vegetation growth barely influences the interpretation of NDVI trend. In terms of the hillslope control sites, the NDVI response is generally weaker on bare soil and saline soil than the above six sites which are located along the river channels (Figure 3). A series of rainfall events between $19^{\text {th }}$ to $22^{\text {nd }}$ December covered the whole study area but the non-vegetated sites did not respond significantly after the rainfall event. 
Table 2. Summary of Analysis Results

\begin{tabular}{|c|c|c|c|c|c|c|}
\hline Site & $\begin{array}{c}\text { Date of Peak } \\
\text { Flow }\end{array}$ & $\begin{array}{l}\text { Peak Flow } \\
\text { Depth }(\mathrm{m})\end{array}$ & $\begin{array}{c}\text { Median } \\
\text { NDVI }\end{array}$ & $\begin{array}{c}\text { NDVI } \\
\text { Increment }\end{array}$ & $\begin{array}{l}\operatorname{Lag} 1^{1} \\
\text { (days) }\end{array}$ & $\begin{array}{l}\operatorname{Lag} 2^{I I} \\
\text { (days) }\end{array}$ \\
\hline $\begin{array}{c}\text { Algebuckina Waterhole, } \\
\text { Neales River }\end{array}$ & $22 / 12 / 2007$ & 3.58 & 0.15 & 0.06 & 29 & 71 \\
\hline $\begin{array}{c}\text { South Stewart } \\
\text { Waterhole, Neales River }\end{array}$ & $22 / 12 / 2007$ & 1.64 & 0.19 & 0.07 & 9 & 17 \\
\hline \multirow{2}{*}{$\begin{array}{c}\text { Algebuckina Bridge, } \\
\text { Neales River }\end{array}$} & $22 / 12 / 2007$ & 2.04 & \multirow{2}{*}{0.21} & 0.11 & \multirow{2}{*}{26} & 27 \\
\hline & $4 / 02 / 2008$ & 0.52 & & 0.09 & & 8 \\
\hline \multirow{3}{*}{ Peake Bridge } & $3 / 11 / 2007$ & 0.49 & \multirow{3}{*}{0.15} & 0.02 & \multirow{3}{*}{28} & 18 \\
\hline & $22 / 12 / 2007$ & 0.59 & & 0.01 & & 35 \\
\hline & $4 / 02 / 2008$ & 0.58 & & 0.05 & & 53 \\
\hline Mid-Peake & - & - & 0.13 & - & - & - \\
\hline \multirow{2}{*}{$\begin{array}{c}\text { Lora Creek, upstream of } \\
\text { Peake }\end{array}$} & $4 / 11 / 2007$ & 0.50 & \multirow{2}{*}{0.18} & 0.02 & \multirow{2}{*}{15} & 10 \\
\hline & $23 / 12 / 2007$ & 1.18 & & 0.03 & & 16 \\
\hline Bare Soil 1 & $22 / 12 / 2007^{\mathrm{III}}$ & - & 0.11 & - & 27 & - \\
\hline Bare Soil 2 & $22 / 12 / 2007^{\mathrm{III}}$ & - & 0.12 & - & 10 & - \\
\hline Saline Site & $22 / 12 / 2007^{\mathrm{III}}$ & - & 0.08 & - & -40 & - \\
\hline
\end{tabular}

I- period from the date of the last peak flow to the following distinctive NDVI increase identified by Worsley Likelihood test;

II- period from the date of peak flow to the following maximum NDVI;

III- expected date of precipitation according to areal flow records.

\section{DISCUSSION}

Comparing the NDVI results between individual sites, it is inferred that the capacity of mapping flow events via MODIS data is affected by various site characteristics. Consequently, site selection is imperative in producing more accurate results via the proposed method. Influences of the major factors are discussed as follows:

1. Flow size: A larger flow size is expected to lead to larger magnitudes of vegetation response and shorter lag periods of significant NDVI increase except at some particular sites where long-term water provision is available. This is supported by a comparison between the moderate flow event in 2007 (lower water stage) and a larger flow event in 2003 (higher water stage) at the same study sites (results are not shown). In terms of the application of the proposed method, flow size is not a factor to be considered in site selection but rather an output of the method as a characteristic of the flow event.

2. Width of floodplain: Wider floodplain with poorly developed channels has been identified as the most favourable factor in improving the accuracy of the proposed method. In this study, those floodplains wider than $1000 \mathrm{~m}$ are characterised by higher increasing rate of NDVI and shorter lag periods of distinctive vegetation response after the flow event, except when the persistence of standing water is long. A wide floodplain also performs better in determining the timing of flow occurrences. It raises the possibility of directly identifying flow events through water responses if the water is not obscured by vegetation. Errors in timing via water responses are within one day.

3. Vegetation type and density: The NDVI responses also appear to be the function of vegetation type and density. Plants of small canopies but higher greenness are favoured in the application of the proposed method. In this study, they lead to relatively high NDVI values with only medium density of coverage and quick response to flow changes. Small plants of lower density are also less likely to block the water surface response. In addition, narrow floodplains or those with narrow vegetation bands introduce unwanted high variance to the entire NDVI time series due to the mixed land cover of bare rocks and plants in one pixel. It can be difficult to identify the vegetation response to flow events from a highly variable NDVI time series. Further research into the NDVI responses of different plant types (e.g. eucalypts versus acacia trees) or functional groups (trees versus annual grasses) would increase our understanding of the role of vegetation type and density on the NDVI response to flow events.

Considering the above factors, one of the ideal sites to apply the proposed method in the study catchment is depicted in Figure 2 as "proposed site". The floodplain at this location is $3300 \mathrm{~m}$ wide and dominated by sparse shrubs which are unlikely to completely block the surface reflectance of open water during the flow events. River channels at this site are shallow and dry out quickly, which means a short water persistence period and floodwaters spread out across much of the floodplain. Selected from the satellite maps without detailed field inspection, this site may even undergo overbank flows rather 
than in-channel flows as the other sites, which means higher flow variance and probably stronger following vegetation responses. The NDVI response at the proposed site can be verified against the flow records of Algebuckina Waterhole which is only $15 \mathrm{~km}$ upstream. The last graph of Figure 3 depicts both clear water and vegetation responses. Errors of direct measurements by the water responses are within 24 hours of the flow occurrences. If water response were not identified, then the date of significant increase in NDVI should be calibrated (13 days in the 2007 flow event) to obtain the date of flow occurrence. The lag time is likely to vary according to site characteristics, flow size and antecedent climate conditions.

The graph of the "proposed site" (Figure 3), which shows apparent correlation between flow records and the NDVI data over time, indicates that this method can be further developed for the modelling of flood volume and extent, and therefore contributes to hydrological modelling which is less sophisticated in arid zones than that of water-abundant areas (Walker et al., 1995). The application of the proposed method for hydrological modelling involves the above three factors as input parameters and may contain other variables such as soil types and channel properties.

\section{CONCLUSION}

Mapping flow events using MODIS is a viable method in arid zones, though the accuracy of timing is affected by various characteristics of the investigated sites. Therefore, appropriate site selection is a crucial process in the application of this remote sensing method. Flow size, floodplain width, and vegetation type and density are considered as the major factors which influence the NDVI response during the flow events; however, flow size is an unknown factor in ungauged or poorly gauged arid zones, and is rather an output of mapping flow events. A wide floodplain with poorly developed channels is generally the favourable feature in site selection, while vegetation type and density should be considered interactively with other site features to avoid adverse impacts on NDVI response.

In terms of timing the flow occurrences, errors of the proposed method are within 24 hours if water response is directly captured. To identify flow size and duration via MODIS is expected to be more complicated and requires comprehensive consideration of all site factors. Mapping the total extent of flood events would require a better understanding of NDVI responses across the range of vegetation types and densities that occur in arid zone rivers.

\section{REFERENCE}

Capon, S.J. (2005). Flood variability and spatial variation in plant community composition and structure on a large arid floodplain, Journal of Arid Environments, 60(2), 283-302.

Costelloe, J.F., R.B. Grayson and T.A. McMahon, (2005). Modelling stream flow for use in ecological studies in a large, arid zone river, central Australia, Hydrological Processes, 19(6), 1165-1183.

Jackson, T.J. (2008). Passive microwave remote sensing for land applications, in Liang S. (ed.), Advances in Land Remote Sensing, Springer, London, 9 -18.

Mertes, L.A.K. (2002). Remote sensing of riverine landscapes, Freshwater Biology, 47, 799-816.

Smith, L.C. (1997). Satellite remote sensing of river inundation area, stage, and discharge: a review, Hydrological Processes, 11(10), 1427-1439.

Ticehurst, C., P. Dyce and J.P. Guerschman (2009). Using passive microwave and optical remote sensing to monitor flood inundation in support of hydrologic modelling, $18^{\text {th }}$ World IMACS / MODSIM Congress, Cairns, Australia, 13-17 July, 2009.

USGS MODIS Reprojection Tool Web Interface (MRTWeb). U.S. Department of the Interior and U.S. Geological Survey, accessed 21 Mar 2011, <http://mrtweb.cr.usgs.gov/>.

Walker, K.F., F. Sheldon and J.T. Puckridge (1995). A perspective on dryland river ecosystems, Regulated Rivers: Research \& Management, 11(1), 85-104.

Weier, J. and D. Herring (2011). Measuring vegetation (NDVI \& EVI), NASA Earth Observatory, viewed 21 Mar 2011, <http://earthobservatory.nasa.gov/Features/MeasuringVegetation/printall.php>.

Westbrooke, M.E. and S.K. Florentine (2005). Rainfall-driven episodic flood events: are they a major factor in moulding New South Wales arid land vegetation patterns?, Australian Geographer, 36(2), $171-181$.

Willem, W.V., V. Frank and F. Jan (2008), Assessment of evapotranspiration and soil moisture content across different scales of observation, Sensors, 8, 70-117. 